\title{
Modelling production system architectures in the early phases of product development
}

\author{
Guð̆laugsson, Tómas Vignir; Ravn, Poul Martin; Mortensen, Niels Henrik; Hvam, Lars
}

Published in:

Concurrent Engineering: Research and Applications

Link to article, DOI:

$10.1177 / 1063293 \times 16669396$

Publication date:

2016

Document Version

Peer reviewed version

Link back to DTU Orbit

Citation (APA):

Guðlaugsson, T. V., Ravn, P. M., Mortensen, N. H., \& Hvam, L. (2016). Modelling production system architectures in the early phases of product development. Concurrent Engineering: Research and Applications, 25(2), 136-150. https://doi.org/10.1177/1063293X16669396

\section{General rights}

Copyright and moral rights for the publications made accessible in the public portal are retained by the authors and/or other copyright owners and it is a condition of accessing publications that users recognise and abide by the legal requirements associated with these rights.

- Users may download and print one copy of any publication from the public portal for the purpose of private study or research.

- You may not further distribute the material or use it for any profit-making activity or commercial gain

- You may freely distribute the URL identifying the publication in the public portal 


\title{
Modeling production system architectures in the early phases of
}

\section{product development}

\author{
Tómas V. Guðlaugsson ${ }^{\mathrm{a}}$, Poul M. Ravnª, Niels H. Mortensen ${ }^{\mathrm{a}}$, Lars Hvam \\ ${ }^{a}$ DTU Mechanical Engineering, Engineering Design and Product Development, Technical \\ University of Denmark; ${ }^{b}$ DTU Management Engineering, Operations Management, Technical \\ University of Denmark
}

\begin{abstract}
This article suggests a framework for modeling a Production System Architecture (PSA) in the early phases of product development. The challenge in these phases is that the products to be produced are not completely defined and yet decisions need to be made early in the process on what investments are needed and appropriate to enable determination of obtainable product quality.

In order to meet this challenge, it is suggested that a visual modeling framework be adopted that clarifies which product and production features are known at a specific time of the project and which features will be worked on—leading to an improved basis for prioritizing activities in the project. Requirements for the contents of the framework are presented and literature on production and system models is reviewed. The PSA modeling framework is founded on methods and approaches in literature and adjusted to fit the modeling requirements of a PSA at an early phase of development. The PSA models capture and describe the structure, capabilities and expansions of the PSA under development.

The PSA modeling framework is tested in a case study and the results indicate that the modeling process facilitates identification of critical factors of the PSA, that the PSA models capture and describe the structure, capabilities, and expansions of a PSA under development, and that the PSA models can facilitate dialogue on the PSA between heterogeneous stakeholder groups.
\end{abstract}

Draft page 1 
Keywords: Production modeling, system modeling, production architecture, production system architecture, production modeling, product architecture, concurrent engineering.

\section{$1 \quad$ Introduction}

When developing a Production System Architecture (PSA), methods exist for describing the product architecture [1-3]; however, when developing a product architecture in parallel with developing new products during technology development, the definition of the products and the production system that existing approaches in literature rely on, are not complete.

To support the development of the production system despite the incomplete definition of both the products and the production system, two approaches may be valuable: (i) Graphically modelling the incompletely defined PSA [4]. (ii) Developing the PSA concurrently with the development of the product architecture that will define the products to be produced by the PSA [5-8]. To accomplish this, however, we need a modelling approach which clearly shows which parts of the product and production system architecture have been defined and stabilized, and which parts are still under development.

Concurrent development of product architecture and a PSA during technology development is illustrated in Figure 1. The production task definition [9] in the early phases includes external factors leading to crucial functional requirements to the production system. In technology developmentcovering Technology Readiness Levels 1-5 [10]—-the product design, product performance, required and obtainable product quality, production processes, and production technologies are still unknown and subjects for consideration by the development team. These uncertainties must be clarified during technology development and the PSA development both affects and is affected by these uncertainties.

The structure of the production system architecture comprises the processing equipment, factory layout, level of automation, organization of the production, planning methods etc. [9]. The production system architecture is derived from the production task, which outlines the functional requirements to the production based on the company's strategy, what needs to be produced and other external conditions 
crucial for decisions regarding the structure of the production system architecture. The production task is in turn affected by what is determined to be feasible during development—what can be produced.

To facilitate the analysis and synthesis in the development project, we need to make the requirements for the production system visual—gradually—as the products are being designed. The design of the PSA requires gradual determination of performance criteria such as cost, required and obtainable product quality, return on investment, volume, scalability of production capacity and product flexibility [9].

This research focuses on modelling a PSA to support both development and implementation decisions during an early phase of development.

\subsection{Structure of the paper}

The remainder of the paper is structured as follows. First the requirements for the model are investigated in section 1.2, by establishing what needs to be clarified during development of the PSA. In section 2, the research aim and method presents the background for the research and how it was performed. In section 3, existing system models and production models in literature are reviewed and compared to the requirements for an early phase PSA model. Section 4 describes the contents of the PSA model and its links to relevant literature. Section 5 describes a case where the PSA modelling framework was applied and the results from implementing the models in the case. Section 6 presents a discussion on the suggested modelling framework based on theory and findings from the case study. Section 7 presents the conclusions from this research.

\subsection{Requirements for a Production System Architecture model}

Clarification of what modelling elements a model of a PSA should contain is needed by identifying relevant production system design factors. A literature search was performed in Google ${ }^{\circledR}$ Scholar ${ }^{\circledR}$ to identify relevant factors using combinations of the search terms "manufacturing”, “manufacturing system”, “production”, “production system”, “technology”, “process”, “design”, “development”, 
“selection”, and “architecture”. Combinations of two or more terms were used to narrow down the number of search results. The titles of the first fifty results (out of thousands) were used to identify potentially relevant papers. The abstracts of these papers were read to further narrow down the number of papers to identify a pool of relevant papers. To support this identification of papers a checklist of production system design from literature was used as a reference [9] concurrent to reading the abstracts. The focus within this work was to identify factors relevant to modelling a production system under development with uncertainties that need to be clarified; to identify and communicate key factors regarding what it is, what it can do, and what it should be able to do in the planned future.

From reading the papers, ten factors were identified, relevant to the three aforementioned categories. The ten factors are categorized in the following section, forming the requirements of what should be represented in the PSA model during technology development.

\subsubsection{Structural elements of a PSA (what is it?)}

- The constituent elements, such as sub-systems, the equipment and workstations [1], and structure, where the structure is the organization of the physical elements and their relations [11].

- Links from a production system's elements and functions to elements of the product architecture through dispositional effects [12].

- Indication of the choice of production technology; a key determinant for achievable functionality of the production system and investments required to implement the production system $[9,13]$.

\subsubsection{Functional elements of a PSA (what can it do?)}

- Product flexibility, as the capability to produce new product variants economically and quickly $[14,15]$ is necessary when the product architecture description is not complete- the aim should be to obtain the right flexibility $[16,17]$. 
- Volume flexibility, as the range of production volume within which the production system can profitably produce products is important in new product introduction [18]

- Processing and setup times, batch sizes, and partially produced goods, as these greatly affect the production system performance $[1,19,20]$.

- Product differentiation points, as these affect product design as well as product and volume flexibility [21].

- Indication of obtainable quality, as quality is generally prioritized over flexibility and should be considered during production system development [22].

1.2.3 Expansions to the PSA (what should it be able to do in the future?)

- Production volume scaling, as moving from a laboratory setting to industrial production scale can require rigorous experiments on industrial production equipment to identify performance parameters and improve obtainable quality [23,24].

- Capabilities, as these can be expanded upon to enable delayed investment for capabilities that are not needed until later on—interfaces between sub-systems are central to facilitating capability expansion [14].

Some of the most critical elements of the production system are the required and obtainable product quality, flexibility for volume and product changes, cost and productivity [9]. As a PSA can be assumed to be incompletely defined during an early phase, a complete model of all these elements may not be achievable or prudent. For example, process technology and scaling principles are highly relevant in the early phases, while batch sizes and setup times are of greater relevance in later phases.

\section{Research aim and method}

This research focuses on developing a modelling framework that captures and facilitates communication of critical PSA parameters belonging to three facets of the PSA - structure, capabilities, 
and expansions - during technology development. In light of uncertainties regarding both the product and production system architectures during technology development, the framework must facilitate a gradual clarification of critical PSA parameters as development progresses. The aim is both to develop and test a modelling framework that supports firms in identifying critical production system development parameters and decisions during technology development. PSA development and parameters need to be clarified across stakeholder groups, so the framework should suit multiple audiences.

\section{$2.1 \quad$ Research method}

The modelling framework was developed on the basis of literature, experience, and feedback from practitioners. The literature foundation was formed by a literature review of theories on systems theories, integrated product development, production system design, production modelling, manufacturing flexibility, process platforms, product architectures, and product family development. The researchers drew on experience from research within product family development, production modelling within product development, and integrated product development from the research. Industrial practitioners provided feedback through testing, as well as providing ideas based on best practices and information on requirements for the modelling framework.

\subsubsection{Testing the modelling framework}

The modelling framework was tested in industry to evaluate whether it would be practical to use in industry, whether critical parameters and decisions would be identified through use of the modelling framework, and whether communication of parameters and decisions with heterogeneous stakeholder groups would be facilitated in the modelling framework.

The researchers' role was to perform the modelling task with input from interviews and workshops with practitioners, along with existing documents describing the production system. Interviews with multiple stakeholders were used to evaluate the use of the models-supplemented by direct observation.

\section{Literature review}

Draft page 6 
The modelling of a PSA during technology development relates primarily to three facets of the PSA: Its structure — to identify processes, critical equipment, and process flow; its capabilities—-to determine what the PSA is capable of producing; and its expansions—-to identify planned and implemented improvements to the PSA's capabilities.

\subsection{Modelling the structure of the PSA}

System modelling has been applied to model the structure, where the structure is the organization of the physical elements and their relations [11]. Production systems can be seen and modelled as large systems $[25,26]$, where the constitutive modelling elements are the individual processing equipment and workstations [26]. The relations between structural elements in the production system primarily take the form of material and tool handling.

Flow models are a common way of modelling the structure of a production system and show the processes of the production system and routing or flow between processes [27]. The detail in process flow models varies, from illustrating only the flow between processes to more detailed models identifying product variant creation, utilizing standardized graphic notations, IDEF or UML modelling formalisms, and links to process simulations and routing optimization algorithms [28-33].

Layout models are primarily used to determine an optimal layout of production equipment within the production facilities [20,34]. They can span entire factories or be limited to a single workstation [4] and are focused on the physical layout and relations between equipment.

\subsection{Modelling the capabilities of the PSA}

Few models depict the capabilities of a production system directly. Some variants of flow models include details such as the product variant differentiation points, which provides an indication of what product variants can be produced by the production system [32]. Layout models may also contain information on capabilities, such as capacity, process, and cycle time [4]. Value Stream Maps (VSM) 
depict the capabilities of the whole value chain, mostly in the form of performance parameters (e.g. processing and cycle times) and may contain similar capability information as layout models [35,36].

Capability modelling can utilize graphical elements such as illustrations of product variants at differentiation points and bar graphs for production volume capacity, e.g. in the Generic Production Flow (GPF) [32], or as numerical data on performance parameters [4,37].

Linking the products to the PSA indicates capabilities and has been done for mature product families using linked models for Bill-of-Materials and for product and process platforms [2,38]. These links are utilized in the production process planning approach, but as they are based on optimization using extensive historical data on products and processes [39], this approach is not fitting for direct implementation during technology development. An integrated model can be used to model the production system with the WIP as an integrated part of the model, but this requires multiple models to model the different states of manufacture and the detailed interactions between the parts and the production equipment [5].

\subsection{Modelling expansions to the PSA}

In literature, quantitative models can compare production technologies on a cost basis with regards to demand and capacity [40], flexibility and uncertainty [41] and the optimal choice of production technology based on investment, costs, capacity capabilities and demand [42]. But these quantitative approaches require input data in the form of demand and cost estimates and lack focus on modelling the constitutive aspect of expansions—-how expansions affect not only capabilities but also structural aspects of the expansion plans. The expansions to a PSA can include modelling multiple layout diagrams to show alternative configurations of a workstation, including performance data on each alternative [4], which enables modelling of both structural and capability expansions using multiple uniform models. A multiple model approach is also used with VSMs, where two maps are generally generated: one for the current state and one for the future, improved, state [36]. 


\subsection{Summary of literature review}

A variety of approaches to modelling the production system from a diverse set of perspectives exist in literature. Structural models facilitate determination and communication of the structure of the production system, but generally lack information on capabilities and expansions. Existing models that include capabilities are focused on mature production systems producing well-defined product families. While many capabilities of the production system are modelled in existing models, the modelling is either limited to a few performance parameters or relies on extensive data sets on products and processes to support optimization of the production system. Extensive numerical data sets are unavailable during technology development and therefore quantitative expansion modelling is not suitable. Modelling expansions to the production system through the use of multiple models showing the differences between 'current' and 'future' states have been successfully applied in industry. However, models have not been found that combine a model of the structure and capabilities of the production system with expansion modelling during technology development.

\section{A framework for modelling the Production System Architecture}

The modelling elements of the PSA modelling framework, illustrated in a generic format in Figure 2, provide information on the PSA from the three distinct perspectives. The structure of the PSA describes what it is by modelling two levels; (i) processes, flows, parts, and tools, and (ii) critical equipment and the definition of product characteristics. The capabilities of the PSA describe what it can do through modelling the product variants produced, the product flexibility and volume flexibility for each main station. The expansion plans describe changes to the structure and capabilities of the PSA that are expected to be realized through investments or other decisions made during the development of the PSA.

\subsection{Structure}


The structure of the PSA is modelled at two levels—a process level and an equipment level—to describe the structure, the production technology choices made, and the dispositional effects between the PSA and the product architecture. The processes are modelled on the basis of function modelling and the GPF $[32,43]$ to describe the processes and the relations between them in the form of interfaces. The equipment level describes critical equipment and workstations and the critical product characteristics that are defined at each of them.

The process level includes individual processes, groups of interlinked processes modelled as main stations, stock, and material handling. Each process is described with a symbol and a note of critical process parameters that are central to increasing the capabilities of the PSA or determining obtainable product quality. The interfaces between processes describe the flow of parts, work pieces, and tools.

The equipment level description emphasizes the dispositional relationship between the PSA and the product architecture [12]. To achieve changes in product characteristics, equipment linked to the definition of the particular product characteristics may need to be updated or changed—and changes to the equipment may affect the product characteristics linked to the equipment.

\subsection{Capability}

The capabilities of the PSA represent the functional aspects of the PSA. They are modelled with an emphasis on product variant creation and system level manufacturing flexibility, which includes process, routing, product and volume flexibilities [44]. Flexibility is modelled to indicate what can be handled by the PSA and what its limitations are, while the product variant creation indicates product differentiation points [21] and relates the PSA to the currently known spectrum of achievable product variants.

Process flexibility enables the production of multiple product variants using the same equipment, enabling higher utilization of machines and the ability to react to changes in market demand between product variants [14]. Process flexibility is communicated by modelling the part related parameter ranges available in the main stations and illustrating the known relevant part types that can be produced. Tools and parts are noted to provide information on what needs to be changed to achieve new product variants. 
Routing flexibility [44] can be modelled as alternative or optional interfaces using dotted lines.

Product related dimensions, geometries, and relevant material parameters that can be handled by the PSA are modelled to allow identification of product variants that can be produced without further investment in the production system. As in the GPF, product differentiation points are modelled to identify the flow for each product variant and the number of product variants that must be handled at each step in the production system [32].

The production volume ranges within which the firm's production can remain profitable are modelled to communicate the volume flexibility [18].

\subsection{Expansion}

The future perspectives of the PSA, including how scaling of the PSA will be implemented are described. PSA implementation decisions during development are necessary to increase the capabilities of the PSA, whether dealing with how to increase capabilities during development or how to ramp up capabilities to prepare for product launch. These changes to the capabilities are the result of changes to the equipment or structure of the PSA and can fall into two categories: Planned expansions for which implementation is to be initiated and potential expansions that are defined but will be implemented at a later stage. Potential expansions carry greater uncertainty. The planned and potential changes to the PSA are modelled either as part of a single model, as in the GPF [32], or as a separate model, similar to current and future state Value Stream Maps (VSM) [37]. Each change in the structure or capabilities is colour coded to emphasize both what the changes comprise and their effect on the PSA's capabilities.

\section{$5 \quad$ Case study}

The modelling framework was applied in a 100 Million DKK technology development project aimed at commercializing transducers based on Electro-Active Polymer (EAP) technology [45]. Development was performed in parallel on the base material, production of the EAP-film and transducers, transducer design, high-voltage electronics design, and technology prototypes utilizing EAP-transducer 
prototypes. The project involved development of equipment and processes for the production of EAP-film and transducers. Specifications, capacity requirements, quality factors, and the supply chain design were constantly changing and being identified during development. Decisions needed to be made on the design and implementation of the production system based on what it would enable in terms of production and development of EAP-products. The design needed to be communicated to diverse stakeholders to ensure that the production system would fulfil the needs of the firm and the project. Experience showed that existing production flow charts were insufficient for this purpose due to lack of information pertinent to the decisions to be made and unsuitability for communication to stakeholders outside the production development team. Reading the existing models did not communicate the effect on production capabilities and external stakeholders requested more specific information on the effect of expansion plans on product flexibility and feasible production quality - in light of the level of investment needed and the uncertainties of technology development, the aims of development and expansion plans needed to be communicated clearly and effectively to a broad group of stakeholders.

The case covers the pilot production of EAP film, a corrugated silicone film sandwiched between metal electrodes deposited onto the film, in various potential configurations [46]. The PSA comprised six main stations, twenty-eight individual processes, and two main flow paths. The number of explicitly stated film variants was twelve, but in addition to this number, thickness and width of the film could be varied by altering production parameters.

\subsection{Modelling process}

Initially, three PSA models were created, each depicting a particular time in the development: (2011) the state before the project started; (2013) the plans being implemented at the time of the modelling activity; and (2015) the intended expansions at the end of the project (shown in Figure 3). The three models were presented on a single large poster that also contained capacity increase estimates and information related to project tasks. Decisions on the development and implementation were made with 
the support of the models. Revised models for the intended expansions at the end of the project were constructed to reflect the decisions.

The modelling process can be divided into three phases as illustrated in Figure 3: initial model construction and data collection; model refinement; and maintaining the models in the project to ensure expansion decisions were reflected in the models. The initial case models were created during a period of one month. This included two workshops with the participation of the production manager, process engineers, and the project manager on behalf of the case firm. Data sources for the models were expert knowledge inside the production team, existing (but outdated) flow chart models of the production system, and detailed walkthrough and analysis of the production facilities. The models were made and implemented as standalone documents in Microsoft ${ }^{\circledR}$ Visio ${ }^{\circledR}$ and $3 \mathrm{D}$ illustrations were created in PTC ${ }^{\circledR}$ CREO ${ }^{\circledR}$ Parametric 1.0. Process icons were made specifically for the novel technology in the case. Large format paper printouts were used for all discussions and workshops.

The PSA models were populated and updated between the workshops as part of model refinement. Feedback sessions were used in combination with model drafts, to increase both the completeness and correctness of the PSA models, as well as adjusting the modelling framework.

The PSA models were maintained over a two-year period where the models were updated as decisions were made regarding expansions of the PSA as the project progressed. The researchers were responsible for updating the software models, while the production manager was responsible for their contents.

\subsection{Production System Architecture models}

The PSA models—see Figure 4—described the structure, capabilities, and expansion of the EAPfilm PSA.

\subsubsection{Structure}

The models captured the elements of the PSA and their relations; the main stations, critical processes, tools, storage and transport of material, and quality control (QC) stations. Each process 
included the primary process parameters that were related to achieving the desired film quality. The main stations were central production equipment or process groups and identified the chosen production technologies in each PSA instance; in the case of the future state PSA model these were the material mixing processes, film coating machine, de-lamination and lamination station, metal deposit machine, pre-conditioning station, and film coating tool cleaning machine.

The equipment level showed the dispositional links between the main stations and product characteristics of the EAP film, i.e. breakdown voltage, film width, and lamination configuration. This identified where the production technologies and equipment affected the obtainable quality of the resulting products.

\subsubsection{Capabilities}

Product flexibility of the main stations was indicated as the available range in major film parameters: film thickness, width, length, and corrugation pattern. Product variant differentiation points were illustrated by basic film configurations. Volume flexibility was indicated as the maximum capabilities as the production task was focused on prototype production and demonstration of production volume scalability. Cycle times for a film roll of a certain length, width, and thickness were noted for each main station in the PSA model of the production system at the outset of the project, and as relative improvements in the current and future state PSA models.

\subsubsection{Expansion}

Decisions to be made regarding investment in new equipment critical to the production process were identified and communicated through the PSA models. Intended and implemented scaling of capabilities were noted as improvements from the PSA at the start of the project. The changes included new equipment, flow path changes, product variant production capabilities, dimensional capabilities, and production capacity capabilities. In the models for 2013 and 2015, updated main stations from the 2011 model were indicated by a green border. The production capacity expansions were noted as relative output increases. 
As shown in Figure 5, the resulting PSA models were used to communicate the intended expansions to the PSA and their expected benefits to other stakeholders, for whom an understanding of the PSA was valuable either for their own work or for making implementation decisions regarding the PSA. The models shown in Figure 5 were used during discussions on the development of the PSA and what to implement in small focused development sessions (5-10 people) and in larger presentations such as during project conferences (15-20 people). Discussions on the benefits of implementing equipmenthighlighted as increased capabilities in the models—and development hurdles led to decisions to change the expansion plans. New model instances were constructed to reflect the changes to the implementation plans. Table 1 lists the main use scenarios for the PSA models in the case project, as well as the main benefit mechanisms in each scenario.

Table 1: Main usage scenarios for the PSA models in the case project.

\begin{tabular}{|c|c|c|c|}
\hline Scenario & Use & Participants & Benefit mechanism \\
\hline PSA analysis and & Poster drafts with in large & Production development & The process of modelling the PSA \\
\hline \multirow[t]{5}{*}{ modelling } & format prints mounted on & engineers; Production & required explicit discussions of \\
\hline & wall; details and additions & manager; Project manager; & details on the production system \\
\hline & noted directly on printout & Modelling experts & and development plans and \\
\hline & & (researchers) & unified the view of the PSA and \\
\hline & & & development plans. \\
\hline Small development & Poster print in large format & Production development & The PSA models provided both a \\
\hline \multirow[t]{5}{*}{ decisions } & mounted on wall; discussed & engineers; Production & holistic view of the PSA and \\
\hline & and notes / adjustments made & manager; Project manager; & details which facilitated analyzing \\
\hline & directly on printout. & & what effect decisions regarding \\
\hline & & & one process had on other \\
\hline & & & processes and development tasks. \\
\hline Communication of & Poster print in large format & Various stakeholders that & Explicit communication of the \\
\hline PSA development & mounted on wall as & were both involved with & processes and capabilities of the \\
\hline
\end{tabular}




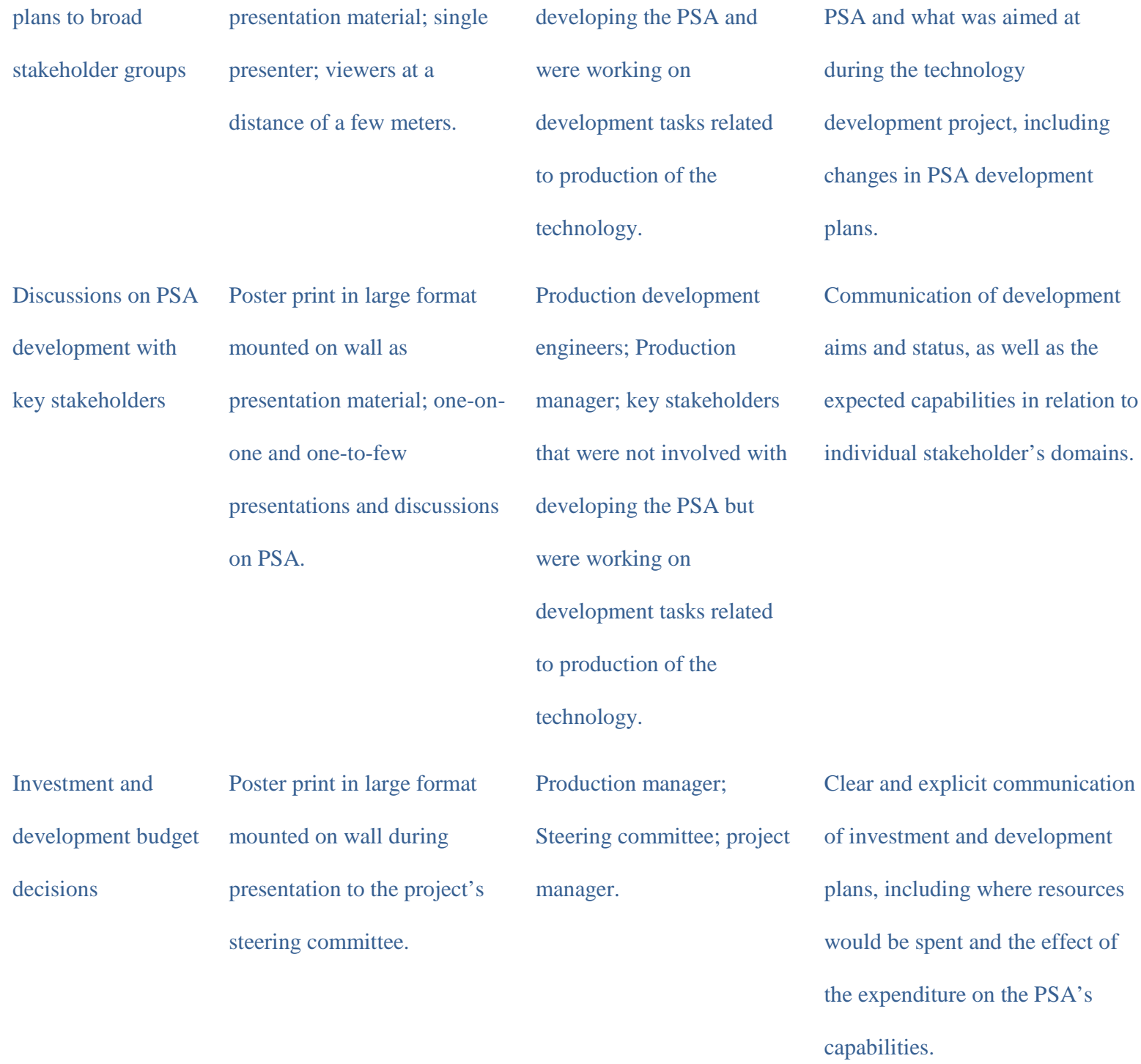

\subsection{Reception of the models in the case project}

The industry implementation facilitated discussions within the production development team on the production and the parameters involved. These were described as being clearer to the team after the modelling process than before. The sheer number of elements of the PSA and parameters involved made the overview provided by the PSA models valued by participants. Some of the statements made by participants on the value of the models are quoted below:

\section{Draft page 16}


- "Hearing how the production team was able to use the models for communication-internally and externally—showed me that it was a good solution. The production team could use it and explain it and use it to explain to others what the production was all about.”

- "The information on the production system that was hidden inside our minds has been visualised in the models"

- "It's good to use with people that do not have the in-depth understanding of what our production system is about”

- "The models give us an overview of the solutions and where potential changes may affect the following processes—-do they have a detrimental effect on the other processes?”

- "We needed to communicate what the activity is, what the process is, and what is critical—-this is captured in the production [system] architecture models”

\section{$6 \quad$ Discussion}

The PSA modelling framework is evaluated against the required contents listed in section 1.2.

\subsection{Structural elements of a PSA}

The structure of the PSA—its sub-systems, equipment, production technologies, and their relations $[1,9,11]$ — is described at a level of detail suitable for use during technology development. The physical elements of the PSA and their functional relations can be identified, while their physical structure and the PSA layout are omitted. The main focus during technology development is to prove the ability to produce products and investigate obtainable quality, which was supported by the PSA modelling framework. The scale required for commercial production volumes—where layout design is important—was not being reached at that point. Identifying dispositional links to the product architecture [12], quality parameters [24], and incorporation of quality control points [22] is supported by the PSA modelling framework.

\subsection{Functional elements of a PSA}


The proposed models include capability descriptions fulfilling the requirements. The PSA models indicated the obtainable product quality, described the capabilities within product flexibility, and plans for scaling up production volume. Batch sizes and processing times were included as scaling volume up to industrial production volumes is an important factor in technology development [23,24], but cost, economical production volume, setup times, and buffers for partially produced goods were omitted as these were considered to be of little relevance during the level of technology development reached within the project.

\subsection{Expansions to the PSA}

The expansion modelling in the case study focused on the expansions to be implemented within the project. Decisions on expansions in the case project were modelled in two ways in the models: (i) The explicit modelling of decisions yet to be made by the production development team and (ii) the implicit modelling of decisions made by the production development team, modelled as planned expansions. The models supported decisions to change expansion plans as the resulting capability expansions were deemed to not be necessary within the scope of the technology development project. System models support decision making through modelling of those consequences of decisions that are most relevant to the aims of the development task [47]. The results of these decisions were then reflected in updated models that showed what was actually implemented and communicated the results to relevant stakeholders.

\subsection{Use of the PSA models}

The industry implementation showed that the PSA models could be constructed within a short time period using a well-known software package using limited resources and were suitably scoped to the needs in the case—important aspects of a model's practicality [48]. 
The feedback from participants clearly stated that the models supported identification of critical parameters and decisions to be made regarding the PSA. The modelling process itself was also noted as a valuable catalyst for discussions and identification of parameters.

The common, simplified perspective [49] provided by the PSA models facilitated exploration of the PSA by heterogeneous stakeholder groups. Observations of the PSA models as focal points for discussions support previous results on the value of architecture models and graphical descriptions as means to facilitate communication between heterogeneous stakeholders $[4,50]$.

\subsection{Research limitations}

Limitations to the research are considered with regard to: number of cases, industry, and development phase. The research is limited to an in-depth study of an ongoing, single case followed closely. The case industry is concerned with discrete manufacturing of rolls of polymer film deposited with thin layers of metal. The main focus of the framework is modelling the production system architecture during technology development to support investment decisions—with uncertainties regarding product and production system architectures. The appropriateness of the framework for other industries has not been empirically evaluated. A limitation on its applicability may also include its use for simpler tasks or in development environments with less uncertainty.

However, while any case can be considered unique, there are elements in the industrial project that can be of relevance for other firms and other industries. Technology development occurs in conjunction with product and production development in other industries where these circumstances also arise [51]. The development of production processes to increase obtainable product quality and production capacity is also described in literature involving other firms [23]. Furthermore, the modelling framework is founded on theoretical literature on systems and production modelling, production system design, and production flexibility. Therefore, it is likely that there are other firms in industry that could benefit from applying this modelling framework. 


\section{$7 \quad$ Conclusion}

During technology development, before the products have been fully defined it is sometimes necessary to invest in production equipment to obtain production capabilities to e.g. determine obtainable product quality on industrial production equipment, produce prototypes, and develop production processes. To obtain fitting production capabilities, what constitutes fitting capabilities and what elements of a production system need to be taken into account must be identified; a decision must also be made on which production capabilities shall be acquired and how. The structure of the production system must be identified, the capabilities of a production system with that structure must be determined, and the expansion of the capabilities through production system development should be decided. A modelling framework, aimed at supporting the development of a Production System Architecture (PSA) concurrently with development of a product architecture from an early phase, the PSA modelling framework, has been proposed. The modelling framework builds upon and combines elements from existing literature to capture and present the structure, capabilities and expansions of a PSA during development. The contribution of this work lies in modelling the combination of structure, capabilities, and expansions during technology development.

A case study has presented the implementation of the modelling approach in industry during technology development with parallel product architecture and PSA development. Case study results indicated that (i) the modelling process facilitated identification of critical PSA parameters; (ii) the framework captured and presented implicit and explicit decisions made, or to be made, by the production development team; (iii) the resulting models facilitated dialogue between heterogeneous stakeholder groups and by confronting recipients with a concrete perspective on the PSA and its capabilities; (iv) the framework is fit for implementation in a dynamic, uncertain, environment at an early phase of development.

The validity of the framework lies in its theoretical foundation and its implementation in a case study in industry. The implementation in an industrial case within the intended environment where 
decisions were made within a heterogeneous group of stakeholders was considered valuable. As the framework is developed on the basis of a broad theoretical foundation and literature has examples of cases where product and production development is performed concurrently from an early phase, it can likely be transferred to other similar environments.

Future research opportunities include further testing iterations to refine the framework, implementing the modelling approach in more projects, implementing the framework in a project where it could be followed from technology development until handover to mature new product development processes, and identifying how the framework can interface with more mature development processes.

\section{Acknowledgements}

The authors want to thank Innovation Fund Denmark for the financial support and the collaborating partners for their role in supporting this research.

\section{$8 \quad$ References}

1. Matt, D.T. (2008). Template based production system design, J. Manuf. Technol. Manag., 19(7):783-97.

2. Jiao, J.R., Zhang, L.L., Pokharel, S. (2006). Process Platform and Production Configuration for Product Families, In: Simpson TW, Siddique Z, Jiao JR, editors. Prod. Platf. Prod. Fam. Des., New York: Springer Science+Business Media, p. 377-402.

3. Prasad, B., Rogers, J. (2005). A Knowledge-Based System Engineering Process for Obtaining Engineering Design Solutions, ASME 2005 Int. Des. Eng. Tech. Conf. Comput. Inf. Eng. Conf., Long Beach, California: ASME, p. 477-88.

4. Jepsen, A.D. (2015). Architecture Descriptions- A contribution to Modeling of Production System architecture, PhD thesis, Technical University of Denmark.

5. Gedell, S., Michaelis, M.T., Johannesson, H. (2011). Integrated Model for Co-Development of Products and Production Systems - A Systems Theory Approach, Concurr. Eng., 19(2):139-56.

6. Prasad, B. (1996). Concurrent Engineering Fundamentals: Integrated product and process organization, Upper Sadle River, NJ: Prentice Hall PTR,.

7. $\quad$ Andreasen, M.M., Hansen, C.T., Cash, P. (2015). Conceptual Design, Cham, Switzerland: Springer,.

8. Prasad, B. (2016). Lean, Integrated \& Connected Framework for developing Smart Products, In: Batalla JM, Mastorakis G, Mavromoustakis CX, Pallis E, editors. Beyond the Internet of Things: Everything Interconnected, DRAFT. Springer-Verlag, p. 1-25.

9. Skinner, W. (1985). Manufacturing - The Formidable Competitive Weapon, New York: Wiley,.

10. Mankins, J.C. (2009). Technology readiness assessments: A retrospective, Acta Astronaut., Elsevier, 65(9-10):1216-23.

11. Hubka, V., Eder, W.E. (1988). Theory of Technical Systems - A total concept theory for engineering design, Berlin: Springer-Verlag,. 
12. Olesen, J. (1992). Concurrent development in manufacturing - based on dispositional mechanisms, $\mathrm{PhD}$ thesis, DTU.

13. Farooq, S., O’Brien, C. (2012). A technology selection framework for integrating manufacturing within a supply chain, Int. J. Prod. Res., 50(11):2987-3010.

14. Jain, A., Jain, P.K., Chan, F.T.S., Singh, S. (2013). A review on manufacturing flexibility, Int. J. Prod. Res., Routledge, 51(19):5946-70.

15. Sanchez, R. (1995). Strategic flexibility in product competition, Strateg. Manag. J., 16(S1):13559.

16. Matta, A., Tolio, T., Karaesmen, F., Dallery, Y. (2010). A new system architecture compared with conventional production system architectures, Int. J. Prod. Res., 38(17):4159-69.

17. Boyle, T., Kumar, V., Kumar, U. (2002). The implementation of manufacturing flexibility: a conceptual framework, In: Ganjavi O, editor. Proc. Annu. Conf. Adm. Sci. Assoc. Canada Prod. Oper. Manag. Div., Winnipeg, Manitoba: I.H. Asper School of Business, The University of Manitoba, p. 52-61.

18. Negahban, a., Yilmaz, L., Nall, T. (2014). Managing production level in new product diffusion: an agent-based simulation approach, Int. J. Prod. Res., 52(17):4950-66.

19. Suh, N.P., Cochran, D.S., Lima, P.C. (1998). Manufacturing System Design, CIRP Ann. - Manuf. Technol., 47:627-39.

20. Russell, R.S., Taylor III, B.W. (2011). Operations management - International Student Version, Hoboken, NJ: John Wiley \& sons (Asia) Pte Ltd.,.

21. Yang, B., Burns, N. (2003). Implications of postponement for the supply chain, Int. J. Prod. Res., 41(9):2075-90.

22. Inman, R.R., Blumenfeld, D.E., Huang, N., Li, J., Li, J. (2013). Survey of recent advances on the interface between production system design and quality, IIE Trans., Taylor \& Francis Group, 45(6):557-74.

23. Galagan, Y., de Vries, I.G., Langen, A.P., Andriessen, R., Verhees, W.J.H., Veenstra, S.C., et al. (2011). Technology development for roll-to-roll production of organic photovoltaics, Chem. Eng. Process. Process Intensif., Elsevier B.V., 50(5-6):454-61.

24. Taguchi, G., Chowdhury, S., Wu, Y. (2004). Robust Technology Development, Taguchi’s Qual. Eng. Handb., Hoboken, NJ, USA: John Wiley \& Sons, Inc., p. 352-76.

25. Hvam, L. (2006). Mass Customization of process plants, Int. J. Mass Cust., 1(4):445-62.

26. Suh, N.P. (1995). Design and operation of large systems, J. Manuf. Syst., 14(3):203-13.

27. Meyer, U.S., Creux, S.E., Weber Marin, A.K. (2006). Process Oriented Analysis: Design and Optimization of Industrial Production Systems, Des. Optim. Ind. Prod. Syst. Boca Raton, Fl: CRC Press,.

28. Perera, T., Liyanage, K. (2000). Methodology for rapid identification and collection of input data in the simulation of manufacturing systems, Simul. Pract. Theory, 7(7):645-56.

29. Oscarsson, J., Moris, M. (2002). Documentation of discrete event simulation models for manufacturing system life cycle simulation, In: Yücesan E, Chen C-H, Snowdon JL, Charnes JM, editors. Proc. Winter Simul. Conf., San Diego, California, USA: IEEE, p. 1073-8.

30. Silla, H. (2003). Chemical Process Engineering - Design and Economics, New York, NY: Marcel Dekker,.

31. Zhang, L.L. (2007). Process platform-based production configuration for mass customization, PhD thesis, Nanyang Technological University.

32. Mortensen, N.H., Hansen, C.L., Hvam, L., Andreasen, M.M. (2011). Proactive Modeling of Market, Product and Production Architectures, In: Culley SJ, Hicks BJ, McAloone TC, Howard TJ, Lindemann U, editors. DS 68-4 Proc. 18th Int. Conf. Eng. Des. (ICED 11), Impacting Soc. through Eng. Des. Vol. 4 Prod. Syst. Des., Kgs. Lyngby: The Design Society, p. 133-44.

33. Prasad, B. (2016). On mapping tasks during product development, Concurr. Eng., 24(2):105-12.

34. De Carlo, F., Antonietta, M., Borgia, O., Tucci, M. (2013). Layout Design for a Low Capacity 
Manufacturing Line: A Case Study, Int. J. Eng. Bus. Manag., 5(35):1-10.

35. Lasa, I.S., Laburu, C.O., Vila, R.D.C. (2008). An evaluation of the value stream mapping tool, Bus. Process Manag. J., 14(1):39-52.

36. Rother, M., Shook, J. (1999). Learning to see - Value stream mapping to create value and eliminate muda, Brookline, MA: The Lean Enterprise Institute, Inc.,.

37. Braglia, M., Carmignani, G., Zammori, F. (2006). A new value stream mapping approach for complex production systems, Int. J. Prod. Res., 44(18-19):3929-52.

38. Jiao, J.R., Tseng, M.M., Ma, Q., Zou, Y. (2000). Generic Bill-of-Materials-and-Operations for High-Variety Production Management, Concurr. Eng., 8(4):297-321.

39. Zhang, L.L., Jiao, J.R. (2013). A graph rewriting system for process platform planning, Decis. Support Syst., Elsevier B.V., 54(2):1174-91.

40. Fine, C.H., Freund, R.M. (1990). Optimal Investment in Product-Flexible Manufacturing Capacity, Manage. Sci., 36(4):449-66.

41. Bihlmaier, R., Koberstein, A., Obst, R. (2009). Modeling and optimizing of strategic and tactical production planning in the automotive industry under uncertainty, OR Spectr., 31(2):311-36.

42. Li, S., Tirupati, D. (1994). Dynamic Capacity Expansion Problem with Multiple Products: Technology Selection and Timing of Capacity Additions, Oper. Res. p. 958-76.

43. Ulrich, K.T. (1995). The role of product architecture in the manufacturing firm, Res. Policy, 24(3):419-40.

44. Sethi, A.K., Sethi, S.P. (1990). Flexibility in manufacturing: A survey, Int. J. Flex. Manuf. Syst., 2(4):289-328.

45. Guðlaugsson, T.V., Ravn, P.M., Mortensen, N.H., Sarban, R. (2014). Front-end conceptual platform modeling, Concurr. Eng., 22(4):267-76.

46. Kiil, H.-E., Benslimane, M. (2009). Scalable industrial manufacturing of DEAP, In: Bar-Cohen Y, Wallmersperger T, editors. SPIE Smart Struct. Mater. + Nondestruct. Eval. Heal. Monit., International Society for Optics and Photonics, p. 72870R - 1-10.

47. Maier, A.M., Wynn, D.C., Howard, T.J., Andreasen, M.M. (2014). Perceiving design as modelling: A cybernetic systems perspective, In: Chakrabarti A, Blessing LTM, editors. An Anthol. Theor. Model. Des., London: Springer London, p. 133-49.

48. Lindemann, U. (2014). Models of Design, In: Chakrabarti A, Blessing LTM, editors. An Anthol. Theor. Model. Des. Philos. approaches Empir. Explor., London: Springer London, p. 121-32.

49. Albers, A., Wintergerst, E. (2014). The Contact and Channel Approach (C\&C2-A): Relating a System's Physical Structure to Its Functionality, In: Chakrabarti A, Blessing LTM, editors. An Anthol. Theor. Model. Des. Philos. approaches Empir. Explor., London: Springer London, p. 15171.

50. Henderson, K. (1991). Flexible Sketches and Inflexible Data Bases: Visual Communication, Conscription Devices, and Boundary Objects in Design Engineering, Sci. Technol. Human Values, 16(4):448-73.

51. Walsh, S.T. (2004). Roadmapping a disruptive technology: A case study The emerging microsystems and top-down nanosystems industry, Technol. Forecast. Soc. Change, 71(1-2):16185.

\section{BIOGRAPHIES}




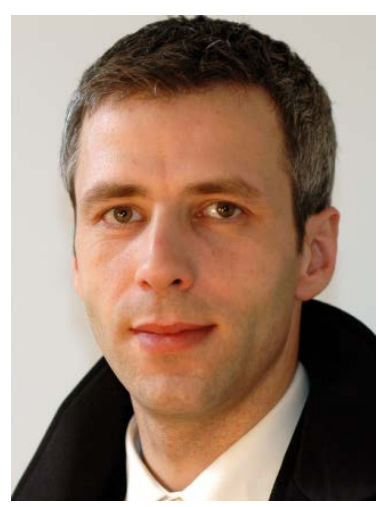

Tómas Vignir Guðlaugsson holds a PhD in Engineering Design and Product Development from the Mechanical Engineering Department at DTU. He has an MSc in Design and Innovation from DTU. His research is focused on the development of Platforms in conjunction with technology development.

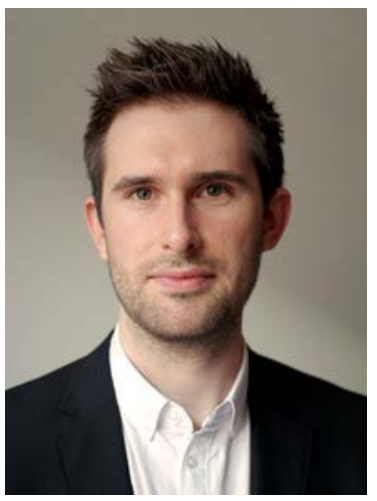

Poul Martin Ravn is a Postdoctoral researcher at the Section of Engineering Design and Product Development in the Mechanical Engineering Department at the Technical University of Denmark (DTU). He holds a PhD in Engineering Design and an MSc in Design and Innovation from DTU. His current research is focused on product architectures and multi-product integration in conjunction with technology development. 


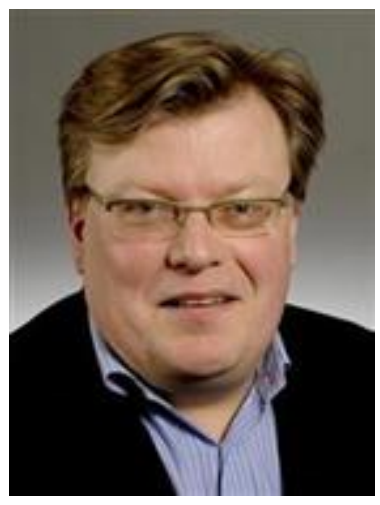

Niels Henrik Mortensen holds a PhD and an MSc in Mechanical Engineering and is employed as a Professor at the Technical University of Denmark. He is head of the section of Engineering Design and Product Development at DTU Mechanical Engineering at the Technical University of Denmark. His main research focus is procedures and methods supporting development of Product Families based on Architectures and Platforms. Currently there are 9 researchers within the field of architecture based product development.

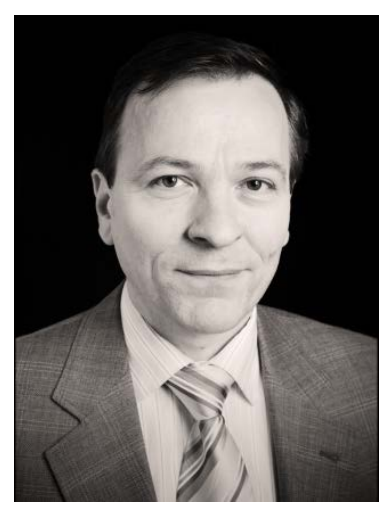

Lars Hvam holds a PhD and an MSc in Engineering and is a Professor in Operations Management at the Technical University of Denmark. His main research focus is product configuration, complexity management, and product modeling. Lars Hvam is currently managing a group of 7 researchers within this research field. 